show upwards of 40 portraits, many of them of great interest and a few unique. They are grouped under the heads of Xanthelasma and its variations, including the sebaceous and sudoriparous forms ; Icteric xanthoma and Glycosuric xanthoma. I must not trespass further on your space than to add that both these exhibitions must be removed in a week or two and that meanwhile anyone wishing to inspect them will be welcome at the Polyclinic, 22, Chenies-street, Gower-street.-I am, Sir, yours faithfully,

June 29th, 1908.

JONATHAN HUTCHINSON.

\section{PRIMITIVE MIDWIFERY IN SOUTH CHINA.}

\section{To the Editor of THE LANCET.}

SiR,--In the very interesting paper by Professor J. B. Hellier on the Methods of Primitive Midwifery, published in ThE LANCET of Feb. 8th, p. 419, the suggestion was made that some readers who have the opportunity of first-hand study of the practices referred to should record their personal experiences. The following observations apply to South China where I am engaged in hospital work. In North and Central China the conditions are different. There, as a rule, women only are allowed to attend to cases of childbirth. Here it is customary for midwifery operations to be undertaken by men as well, and no objection is made to their presence Naturally, in a Chinese inland town one sees cases which, owing to prolonged labour without assistance, are rarely met with in English practice. One of my first introductions to Chinese midwifery work took place in a village where the woman had been in labour for some five days. The child was a monster with one head, two bodies, four arms, and four legs. The uterus was already ruptured and two of the legs had gone through the rent. Fortunately the resisting powers of the Chinese peasant woman are great. She lives a much more natural life than her Western sisters, and if she has to do more than her share of the rough work in the fields she reaps the benefit when the time comes for the birth of a child.

Professor Hellier divides the development of obstetrics into three stages. China is undoubtedly still in the primitive stage, characterised by an entire absence of knowledge of anatomy and the mechanism of labour. Native doctors, for instance, are taught that in normal labour the child makes its first appearance with the face looking to one side. If it looks downwards it portends the death of the father ; if upwards, it portends that of the mother. The treatment resorted to is often cruel in the extreme and as senseless as cruel. It is indeed a wonder that the inhabitants of a country which has been civilised for so many centuries and has shown so much ingenuity and inventive power in the past should have failed to grasp the very elements of midwifery practice.

There is probably no race more fond of all sorts of medicine than the Chinese. Pills, plasters, ointments, concoctions of every variety are always acceptable by the sick Celestial. Consequently one is not surprised at the large number of internal and external remedies for difficult labour. Most of these are given with a view to strengthening the pains. The administration of urine, mentioned by Professor Hellier, is not confined to the Dutch East Indies. In South China it is a well-recognised remedy. But it is always children's urine that is drunk, and almost invariably that of a little boy. Contrary to what one might expect, opium is rarely given. A pheasant ripped open while still alive and placed on the abdomen is supposed to be efficacious, but not so much so as a tiger's intestines. These are worn round the neck with the ends hanging down. Being an expensive remedy, they are usually borrowed for the occasion from some neighbouring medicine shop which keeps them in stock. The midwife is usually an old woman of most uncleanly habits who probably has been summoned from her fields for the occasion and who has had neither time nor inclination to first wash her hands. Even in normal labour she is responsible for a lot of suffering, but it is when delivery is delayed that she does most harm. There are no forceps in Chinese native practice. If the child does not appear after what is judged to be the proper time the nidwife inserts her hand and attempts to pull at the first thing she can catch hold of. On one occasion I was called to a case of placenta prævia where the woman had been bleeding badly for some 60 hours. Largely owing to the attentions of the midwives, $I$ found presenting at the vulva the cord, a piece of the placenta, one foot, and two arms. If pulling at the first part which comes to hand prove unsuccessful recourse is had to a knife and the whole vulva is often torn and cut in a most barbarous manner, the urethra not infrequently being irremediably damaged. On two or three occasions I have seen the vulva and the rectum made into one large cavity and the woman almost pulseless from loss of blood. I have felt incisions all round the cervix comparable to the first steps of vaginal hysterectomy. Once I found that somehow or other the native doctor had forced apart the symphysis pubis so that there was a space of an inch between the two pubic bones and a finger could be inserted for two and a half inches into the carum Retzii.

With such methods of treatment, transverse presentations are naturally very dangerous, and as a matter of fact such cases, not within reach of a foreign-trained doctor, almost invariably die. The treatment pursued is to place a little rice or a few cash into the hand and then to push it back with the idea apparently that having received a present the child will consent to come down in the right way. The next step is to pull on the hand. Sometimes the other arm is brought down, making delivery more difficult still, but I have only seen this once. Usually the further treatment of the case resolves itself into pulling more and more energetically until the woman dies from exhaustion or ruptured uterus. Embryotomy is never done purposely. Sometimes an energetic midwife will open the head in her endeavour to deliver, but this is considered bad practice. As a rule, in cases of impacted head injuries to the child due to the midwife are confined to the scalp, which may be torn right off.

The Chinese have a great horror of a woman dying with the child still unborn. In not a few cases the foreign doctor arrives upon the scene when the woman is just on the point of death. Naturally, in these circumstances, one does not like to interfere, especially if the woman happens to live in a distant village where no foreigner has been before and where consequently there is a crowd of some hundreds of interested onlookers outside the door. The greatst pressure is brought to bear upon the doctor to undertake the case. The oldest man in the family, of most venerable appearance, will come personally to make the request. Once I have had my chair sent away "with the intention of keeping me in the house until the child was born. The death of the woman seems unimportant compared to the necessity of delivering the child. A woman who dies in childbirth with the child undelivered is supposed always to remain in hell, and her spirit, never at rest, is believed constantly to harass the family and bring all manner of ill-fortune upon each member. With a view to avoiding this the Chinese sometimes perform Cæsarean section. I have never heard of the operation being attempted when the woman is alive. It is done after death. The operation is performed by one of the local coffin-bearers who form, perhaps, the most degraded class in Chinese society. A nurse informs me that the customary fee is five Mexican dollars, about a month's wages for an ordinary coolie.

A curious superstition among the Chinese women is that sometimes the child is born viâ the rectum. To prevent this some Chinese women refuse to lie down for delivery but sit firmly on their wooden bedboards until the head appears. A few months ago at the house of the local chief magistrate we had for this reason great difficulty in persuading a woman to allow us to attend to her in the ordinary position. I remember this case well as the chief lady of the Yamen was herself an amateur Chinese doctor. She dosed the other women of the establishment with their children, like Mrs. Squeers, and they dare not refuse. I was told privately that she had already killed five or six infants in this way. At the time of the operation it was not etiquette for her or the other wives to be present. I thought I heard some breathing behind my back and looking round found a screen through which several holes had been bored. At each hole there appeared an eye !

As a rule the Chinese midwife does not pull upon the cord in a case of normal labour, and it is to her credit that she will wait for two or three hours for the placenta to be delivered naturally. The woman is given various drugs and 
foods. Sometimes she is made to romit and then, as mentioned by Professor Hellier, her own pigtail may be used for the purpose, being thrust down the throat. Should this be of no avail the cord is pulled upon or a special midwife is :summoned who, without any previous cleansing, thrusts her hand into the uterus and brings out parts of the placenta. 'The umbilical cord is left long. It is not cut with a knife or scissors but severed with a broken piece of crockery or bitten through with the teeth. A large number of children die from infection at the umbilicus. The child is usually washed on the third day after birth. When the next bath is given is very indefinite. The baby is fed with rice and cakes on the first day of its existence. I have noticed that the boat women sometimes chew the rice themselves before giving it to the infant. No doubt this assists the child's digestion by supplying some of the stareh-converting ferment which is lacking in the infantile economy, but as a rule the rice and cakes are given in the same way as they would be given to an adult. It is not to be wondered at that in these circumstances the mortality among new-born children from digestive complaints is very great.

I am, Sir, yours faithfully, Philip Rees, B.A., B.Sc., M.B. Lond., Surgeon to the Customs, Wuchow.

Wesleyan Hospital, Wuchow, China, April, 1908.

\section{TRICHOPHYTON AND MICE.}

\section{To the Editor of THE LANCET.}

SIR,-It may be of interest to your readers if I mention a coincidence that happened to me in connexion with the above subject. Some three years ag.o I mounted a section of a mouse's testicle and on examining it found it contained a most perfect specimen of pure culture trichophyton. This specimen was put amongst my collection. Some few weeks ago a medical man sent me two tubes of pure ringworm from London to mount four specimens of trichophyton, four of microsporon; in all I mounted about 20. But there was one beautiful specimen and this I compared with the specimen mounted from the mouse; I find the two specimens are exact.

I am, Sir, yours faithfully,

Maldon, Essex, June 29th, 1908.

Charles DibBex.

** We understand that in the laboratory at St. George's Hospital there has been an epidemic of trichophyton in the mouse. The condition was at first thought to be favus but culture showed it to be a microsporon. It caused some vlceration, indeed the skull seemed to be destroyed by it in places, and possibly some such similar condition might account for the condition observed by Mr. Dibben in the mouse's testicle.-ED. L.

\section{THE STRAWBERRY SEASON.}

\section{To the Edrtor of THE LANCET.}

SIR,-The interesting annotation which appeared in THE LANCE' of June 20th in re "the strawberry season," suggested to me in the course of perusal that some of your readers might be glad to know that the semi-popular idea that the strawberry is "good for the gout"-as well as for some other things - is one which has been stamped with the ihighest botanical authority. The name of the great Swedish physician Linnæus is pretty surely known to most readers of the present generation only as that of the great student of natural history and founder of the modern science of botany, not of the active medical practitioner which he actually was during the greater part of the period of his most original researches. In his native land of Sweden, as might be expected from a soil and people of strangely romantic history, inspiring scenery, and somewhat uncanny meteorology, the folk-lore medicine of the people, the miracle methods of the clerics, the faith-cure of the quack pretender, and the witchcraft treatment of the wrinkled sorceress, for many centuries included the bulk of the practice of the healing art as carried out in that country. Herbal cures, ranging in value from that of the "All heal "-ing mistletoe downwards, were largely employed by the people of all the Scandinavian territories. One of the medicinal products of the vegetable kingdom which have been iargely used by the Swedish people is the wood strawberry, and the belief in the therapentic efficacy of this fruit has been by no means confined to the peasantry and the unlearned vulgar. Linnæus himself has placed on record the fact that by eating of this fruit he was able to bring a violent attack of gout to a precipitate conclusion, and for the remainder of his life he consumed a maximum quantity of fresh strawberries. There was thus a very good precedent behind the attempted boom of the "strawberry cure of gout" which was made in the latter years of the past century, although the "discoverers" of the "cure" did not, so far as I can remember, quote that authority! And it is of interest to add in this association a passing reference to a still more remarkable specimen of folk-lore prescience of recent-" modern "-discovery in the domain of scientific therapeusis : the Swedish appreciation of the wintergreen, which has been time out of mind recognised by the peasantry of that country as a "miraculous" cure for rheumatism, and is on that account popularly known by the highly expressive epithet of Stat up ach gatt (Stand up and walk)

Dublin, June 23rd, 1908.

I am, Sir, yours faithfully,

\section{CHILDREN'S COUNTRY HOLIDAYS FUND.}

\author{
To the Editor of THE LANCET.
}

SIR,-The delightful weather of the early summer brings to the minds of your readers happy memories of pleasant holidays spent abroad or at the seaside or in the country and is turning their minds to the days when they will again leave London. May we remind them of the needs of the poor children of London, most of whom have no such happy memories confined as they are to the streets.

The Children's Country Holidays Fund, which is now entering on its twenty-fifth year of work, exists to send the poor children of London into the country for a fortnight's holiday, with cottage hosts. All children between the ages of five and 14 attending the elementary schools are eligible without distinction of creed; and in all cases where they can, the parents contribute towards the cost. Last year 41,970 enjoyed a fortnight in the country. May we ask your readers to help us to send 50,000 this year? Every guinea subscribed will provide a fortnight's holiday for two children. All donations, large or small, will be gratefully acknowledged by the Hon. Treasurer, the Earl of Arran, 18, Buckinghamstreet, Strand, W.C.

We are, Sir, yours obediently,

ALFRED LYTTELTON I Trustees of the Children's

W. F. D. SMrTH Country Holidays Fund.

Buckingham-street, Strand, W.C., June 23rd, 1908.

\section{DIRECT EXCRETORY IRRITATION}

\section{To the Editor of THE LANCET.}

SIR,-On p. 1776 of your issue of June 20th you have a review of Dr. Norman Walker's new edition of "Introduction to Dermatology." The writer therein remarks: "We agree with the author that most of the substances causing urticaria certainly act as toxins on the skin, probably as they are being excreted, and that they do not cause the disease merely by reflex irritation, as is still often taught," and so on. This passage confirms my theory of the origin of many symptomatic skin rashes by direct excretory irritation. It was first published at the Birmingham meeting of the British Medical Association some 18 years ago. Later, it was somewhat more elaborated in a little volume " Excretory Irritation," published in 1897. The theory has passed through the early stages of derision and neglect and is now virtually adopted by implication in the writings of various dermatologists. Dr. Norman Walker, however, is the only dermatologist who has so far formally and publicly acknowledged my position in the matter-and he has done so in several past editions of his book. To the latter fact I venture to call the attention of your reviewer. Personally I have always been content to accept the position that if my theory attains the established dignity of a general law the question of authorship does not much matter. At the same time I am sure THE LANCET would wish its readers to be accurately informed upon a point of the kind.

I am, Sir, yours faithfully,

Bryanston-street, W., June 29th, $1908 . \quad$ DAVID WALSH. 